\title{
3D visualization of TiO2 nanocrystals in mesoporous nanocomposite using energy filtered transmission electron microscopy tomography
}

\author{
Gondo, Takashi; Kasama, Takeshi; Kaneko, Kenji
}

Published in:

Microscopy (Oxford, England)

Link to article, DOI:

10.1093/jmicro/dfu081

Publication date:

2014

Document Version

Publisher's PDF, also known as Version of record

Link back to DTU Orbit

Citation (APA):

Gondo, T., Kasama, T., \& Kaneko, K. (2014). 3D visualization of TiO2 nanocrystals in mesoporous nanocomposite using energy filtered transmission electron microscopy tomography. Microscopy (Oxford, England), 63(suppl 1), i27. https://doi.org/10.1093/jmicro/dfu081

\section{General rights}

Copyright and moral rights for the publications made accessible in the public portal are retained by the authors and/or other copyright owners and it is a condition of accessing publications that users recognise and abide by the legal requirements associated with these rights.

- Users may download and print one copy of any publication from the public portal for the purpose of private study or research.

- You may not further distribute the material or use it for any profit-making activity or commercial gain

- You may freely distribute the URL identifying the publication in the public portal 
rod- and plate-like morphologies with homogeneous dispersion in GdBCO. In addition, growth directions of these precipitates were found with wide angular distributions from growth direction of GdBCO. Anisotropy of $J_{c}$ in the magnetic fields was probably enhanced by various growth directions and homogeneous dispersion of nanosized BHO within GdBCO.

\section{References}

1. Takahashi K, Yamada Y, Konishi M, Watanabe T, Ibi A, Muroga T, Miyata S, Shiohara Y, Kato T, Hirayama T (2005) Magnetic field dependence of $J_{\mathrm{c}}$ for Gd-123 coated conductor on PLD-CeO ${ }_{2}$ capped IBAD-GZO substrate tapes. Supercond. Sci. Technol 18: 1118-1122

2. Tobita H, Notoh K, Higashikawa K, Inoue M, Kiss T, Kato T, Hirayama T, Yoshizumi M, Izumi T, Shiohara Y (2012) Fabrication of $\mathrm{BaHfO}_{3}$ doped $\mathrm{Gd}_{1} \mathrm{Ba}_{2} \mathrm{Cu}_{3} \mathrm{O}_{7-\mathrm{y}}$ coated conductors with the high $I_{\mathrm{c}}$ of $85 \mathrm{~A}=\mathrm{cm}-\mathrm{w}$ under $3 \mathrm{~T}$ at liquid nitrogen temperature (77 K). Supercond. Sci. Technol. 25: 062002

doi: 10.1093/jmicro/dfu080

\section{D visualization of $\mathrm{TiO}_{2}$ nanocrystals in mesoporous nanocomposite using energy filtered transmission electron microscopy tomography}

Takashi Gondo ${ }^{1, *}$, Takeshi Kasama ${ }^{2}$, and Kenji Kaneko ${ }^{1}$

${ }^{1}$ Department of Materials Science and Engineering, Kyushu University, 744 Motooka Nishi-ku Fukuoka, 819-0395, Japan, and ${ }^{2}$ Center for Electron Nanoscopy, Technical University of Denmark, Building 307, DK-2800 Kongens Lyngby, Denmark

*To whom correspondence should be addressed. E-mail: 3te11019m@s.kyushu-u.ac.jp

\section{Introduction}

Mesoporous silica, SBA-15, is one of the best candidate for the supporting material of catalytic nanoparticles because of its relative large and controllable pore size and large specific surface area [1]. So far, various nanoparticles, such as $\mathrm{Au}, \mathrm{Pt}$ and $\mathrm{Pd}$, have been introduced into the pore for catalytic application [2]. The size of nanoparticles supported inside SBA- 15 is restricted by that of the pore, and they are usually ranging from $2 \mathrm{~nm}$ and $50 \mathrm{~nm}$ in space.

It is necessary to anchor the nanoparticles within pores to avoid segregation / sintering of them. However, it is difficult to anchor them within pores in the case of use of deposition-precipitation method due to extreme low iso-electric point (IEP) of silica $(\sim 2)$. Therefore, $\mathrm{TiO}_{2}$ nanocrystals (IEP 6-8) were then introduced to anchor AuNPs [3].

In this study, EFTEM tomography was applied to examine the effectiveness of $\mathrm{TiO}_{2}$ for AuNPs.

Materials and method

$\mathrm{Au} / \mathrm{TiO}_{2}$-SBA-15 was embedded into epoxy resin for electron microscopy and microtomed to about $30 \mathrm{~nm}$ thickness. EFTEM-tomography was operated at $120 \mathrm{kV}$ and using Ti-L ionization edge via threewindow method. Prior to EFTEM, STEM-HAADF tomography was also carried out for visualizing AuNPs and for comparison.

Result and discussion

Figure 1 shows 3D-volume of AuNPs and $\mathrm{TiO}_{2}$ nanocrystals from EFTEM-tomography. $\mathrm{TiO}_{2}$ nanocrystals in the porous material were successfully visualized using EFTEM -tomography, and local relationship between AuNPs and $\mathrm{TiO}_{2}$ nanocrystals were revealed. A large number of $\mathrm{TiO}_{2}$ nanocrystals were randomly distributed in the SBA-15. It was found that most AuNPs were directly on the exposed $\mathrm{TiO}_{2}$ nanocrystals. It implies that $\mathrm{TiO}_{2}$ nanocrystals were exposed on the surface of the pore and anchored AuNPs inside the pores.

Key words: EFTEM, 3D-Electron tomography, Mesoporous silica, $\mathrm{TiO}_{2}$, Au, nanoparticle

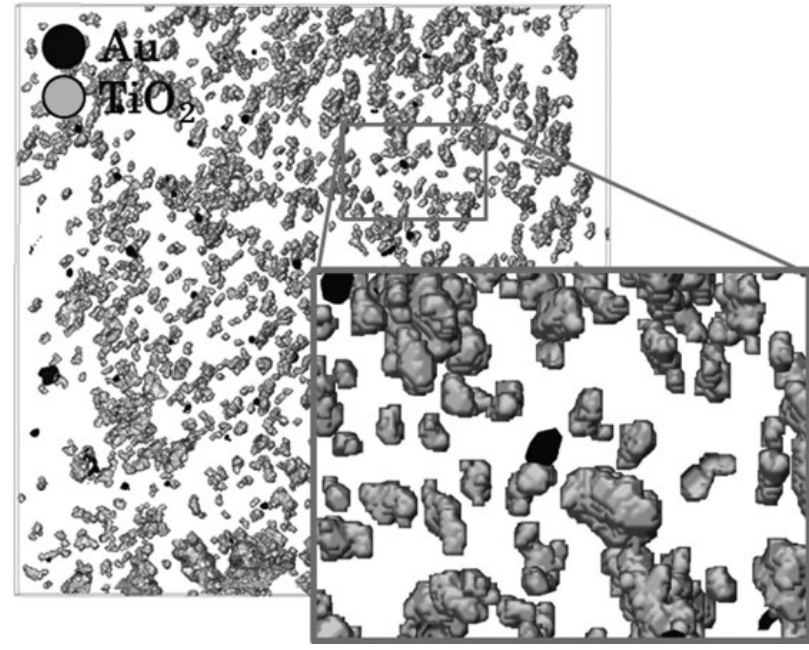

Fig. 1. 3D volume of AuNPs and $\mathrm{TiO}_{2}$ nanocrystals

\section{References}

1. Zhao D., Feng J., Huo Q., Melosh N., Fredrickson G.H., Chmelka B.F., Stucky G.D. (1998). Triblock copolymer syntheses of mesoporous silica with periodic 50 to 300 Angstrom pores. Science 279, 548-552.

2. Zhu J., Konya Z., Puntes V.F., Kiricsi I., Miao C.X., Ager J.W., Alivisatos A.P., Somorjai G.A. (2003). Encapsulation of metal $(\mathrm{Au}, \mathrm{Ag}, \mathrm{Pt})$ nanoparticles into the mesoporous SBA-15 structure. Langmuir 19, 4396-4401.

3. Takashi G., Kenji K., Takeshi N., Kazuhiro Y., Zineb S., Jonathan S.B., Paul A.M., (2014). Microstructural Analysis of $\mathrm{Au} / \mathrm{TiO}_{2}$-SBA-15 Nanocomposite. Microscopy and Microanalysis 20, 1001-1007.

doi: 10.1093/jmicro/dfu081

\section{Microstructural characterization of $\mathrm{GdBa}_{2} \mathrm{Cu}_{3} \mathrm{O}_{7-\delta}$ superconductor films with $\mathrm{BaHfO}_{3}$ artificial pinning centers by scanning transmission electron microscopy}

Kazuhiro Yamada ${ }^{1}$, Takeshi Nishiyama ${ }^{1}$, Kenji Kaneko ${ }^{1}$, Yukio Sato ${ }^{1}$, Ryo Teranishi' ${ }^{1}$, Takeharu Kato ${ }^{2}$, Akira lbi $^{3}$, Masateru Yoshizumi ${ }^{3}$, Teruo Izumi ${ }^{3}$, and Yuh Shiohara ${ }^{3}$

${ }^{1}$ Department of Materials Science and Engineering, Kyushu University, 744 Motooka, Nishi-ku, Fukuoka 819-0395, Japan, ${ }^{2}$ Nanostructures Research Laboratory, Japan Fine Ceramics Center, 2-4-1 Mutsuno, Atsuta-ku, Nagoya 456-8587, Japan, and ${ }^{3}$ HTS Conductor Processing \& Power Application Division, International Superconductivity Technology Center, 3-2-1 Sakado, Takatsu-ku, Kawasaki 213-0012, Japan

Critical current $\left(I_{\mathrm{C}}\right)$ of superconductor films under magnetic field is strongly influenced by dispersions and morphologies of artificial pinning centers (APCs) in general [1]. $\mathrm{BaHfO}_{3}(\mathrm{BHO})$ is acknowledged as the best candidates of APCs for REBCO films, which shows utmost thickness dependence and isotropic angular dependence of $I_{\mathrm{C}}$ values for REBCO films [2]. Moreover, several researchers have focused on the nanostrains caused by the lattice mismatch at the interface between APCs and REBCO matrix, which are also the source for enhanced vortex pinning of the REBCO films [3]. In this study, we investigated to examine the nanostrain at the interface using spherical aberration $\left(\mathrm{C}_{\mathrm{S}}\right)$ corrected scanning transmission electron microscopy (STEM). 